\title{
Innovation in K-12 Education: One District's Journey
}

\author{
Daniel Forbes (University of Minnesota) \\ Eric Schneider (Minnetonka Public Schools)
}

\author{
KEYWORDS: Educational Services, Public \\ Administration \& Government, Innovation, Organization, \\ Leadership.
}

The United States' system of K-12 public education is an important cornerstone of American society. Public schools play a critical role in advancing our widely valued principles of community and opportunity. At the same time, public discussions of the U.S. educational system often reveal high levels of frustration and contention. In many districts, teacher morale and public confidence are low, and this has led some people to wonder how the system will meet the needs of students in a rapidly evolving society (e.g., Goldstein, 2015; Russakoff, 2015).

We believe public schools can rise to the challenges they face, and we think innovation has an important role to play in helping them do so. When we refer to innovation, we don't have in mind a "quick fix." And we're mindful of the fact that some quarters of the educational system are feeling "innovation fatigue." Very often, past innovative efforts have failed to engage teachers and others who work most closely with students - the very people who often have the most insight and expertise relevant to improving the way schools work. But as tempting as it might be to give in to innovation fatigue, we think school systems need to keep exploring avenues for innovation and to share ideas about innovation programs that manage to bring communities together for the benefit of students.

In an effort to stimulate that kind of exploration and conversation, we offer in this article an overview of a district-wide innovation program that has succeeded in fostering employee-enabled, school-based innovation. In the sections below, we'll describe the basic features of this program, and we'll offer some insights that may be useful to other districts seeking to advance their own innovation programs.

\section{Overview}

The program we describe took root in Minnetonka

Public Schools (MPS), a suburban school district in the greater Minneapolis area. As one of the largest school districts in the state of Minnesota, MPS serves more than 10,000 students and employs more than 750 teachers. The MPS program was led by Eric Schneider, one of the authors of this article, and it was implemented through a partnership with Optum, a health services and innovation company based in Eden Prairie, Minnesota.

About nine years ago, in 2008, MPS Superintendent Dr. Dennis Peterson set out to build a culture of innovation within the district. He took inspiration from John Kotter's 2006 book Our Iceberg Is Melting: Changing and Succeeding Under Any Conditions, which lays out a series of steps for organizations seeking to cultivate innovation. Consistent with Kotter's advice, MPS assembled an Urgency Team, which was tasked with communicating a sense of urgency for innovation, as well as a Guiding Team, which was tasked with guiding the emerging innovation system and building internal structures to fuel the effort.

MPS then adopted the crowdsourcing software Spigit to provide a platform that would allow all staff to take part in the innovation process. It then kicked off its first innovation event: an "Idea Hunt". This event was a great success, generating more than 100 ideas from staff across the district. However, staff found it difficult to work with the Spigit software. Ultimately, the team chose to combine the crowdsourcing software with a team of innovation coaches who could provide the knowledge and expertise to develop the ideas and the culture of innovation. After carefully considering and selecting among those ideas, the district chose to develop a profession-based concept that would offer high school Juniors and Seniors an opportunity to gain unique real-world experiences. The program - called VANTAGE - integrates high-level, core curriculum in an off-site professional environment where teachers engage students in solving real business problems 
submitted by local business partners. The idea was submitted by two social studies teachers at the high school - teachers who later went on to speak at national conferences about the program and its development as well as consult with other districts currently replicating the program.

The Idea Hunt went on to become an annual event in the district. The second Hunt captured more interest from staff. However, the district continued to rely heavily on the expertise of the Guiding Team for the ultimate selection of ideas, and some staff felt frustrated over whether this process was sufficiently transparent. Nevertheless, three ideas from the Second Hunt received School Board approval for further development:

- A high-level online learning platform, later branded as "Tonka Online"

- A new E-12 core curriculum in the area of computer programming, later branded as "Tonka <codes>"

- A summer learning platform that would expand learning options for middle-level students during the summer months, later branded as Summer Academy

Tonka Online focused on replicating the high-quality experience of the brick-and-mortar classroom in a virtual environment, and it successfully launched in Summer 2014. Summer Academy enrolled more than 200 students the same summer with a variety of STEM and Arts options. Then in Fall 2014, "Tonka <codes>" launched with $300 \mathrm{~K}-5$ teachers trained in the new computer programming curriculum.

The Third Idea Hunt yielded even further engagement from the staff. Collectively, staff submitted 182 new ideas for consideration, and more than half of all staff members participated in the submission or consideration of ideas. By contrast, organizations that use crowdsourcing tools typically expect to attract only 15 to $20 \%$ of their workforce.

A key change that occurred at this stage was that the district began to focus more on "small" and "medium" ideas, not just the "big" ones. Staff input had made clear that seemingly small requests could still have big impacts on staff members and students. Accordingly, many smaller ideas were given the resources and permission to move forward. Another key change motivated by staff input was the introduction of "Innovation Coaches." These were individuals who engaged in on-site, face-to-face interactions that supplemented Web-based interactions and who helped serve as liaisons between staff and Guiding Team leaders. Thanks to both of these changes, district staff became increasingly comfortable with MPS' innovation processes. Teachers, counselors and others came to regard the innovation process as something that had demonstrated its ability to benefit them and their students, and they felt they had voice and influence in the innovation process.

\section{Implications}

The experience of the MPS program carries several lessons relevant for people in other school districts seeking to advance their own innovation programs.

1. Start with teams \& tools. Successful organizational innovation requires input and cooperation from a wide variety of people. So when launching an innovation program, it can help to assemble teams of people from different levels of the organization as well as people with different roles and backgrounds. Teams continue to be important along the journey too, because implementing and refining specific innovative initiatives often requires ongoing listening and guidance throughout an organization. It is helpful for team members to agree up front on which innovation-related tools and frameworks they will use. Many such tools are available today, including the Kotter and Rathgeber (2006) book that MPS used as well as variants of the "design thinking" approach (e.g., Brown, 2008). But it's not essential for districts to use any particular tool. What matters more is that program teams have a strong collective commitment to learning and exploration.

\section{Enable staff to identify and champion} improvements. Often innovative efforts fail because they are "imposed" on an organization by people at the top or people on the outside. District-wide innovation programs are likely to be more successful to the extent they focus on empowering district employees to identify and lead specific innovative proposals. This approach leverages the "on-the-ground" knowledge of people who have intimate 
experience working within the district. Those people are often in the best position to understand students' specific needs as well as how to work with the district's own schools and communities in meeting students' needs. In addition, the employee-enabled approach engenders a sense of local "ownership" with regard to the innovation program. Teachers, parents and others are more likely to gain confidence in proposals that they know are being designed and led by people from within their own districts. That confidence, in turn, helps foster the kind of in-depth collaboration that is so often critical to developing and implementing an innovative proposal.

3. Screen and test new ideas. Very few innovative ideas are born perfect. Many new ideas prove to be flawed or unworkable, and others may need significant refinement to achieve their intended effects. Once again, district staff should participate actively in evaluating new ideas, thereby helping to identify those that merit further development. For the best ideas, it is best to design small-scale tests to help clarify how well the idea will work in practice. This approach helps the district to further select and refine innovative ideas before making large-scale investments of time and resources. To the extent that early-stage testing data indicate that an idea is working well and shows further promise, the size of the test should expand. Well-developed and well-proven ideas can then be integrated into the larger ecosystem of the school district. This kind of "structured experimentation" is common to the innovation programs adopted by many contemporary for-profit and non-profit organizations.

4. Celebrate effort along with success. For an innovation program to be successful, people need to feel comfortable proposing new ideas. As ideas are vetted, therefore, it's important to continually validate all innovative efforts, including those that turn out to be less successful. Many people will find that their ideas don't gain traction on the first or second try. But those same people may still have great ideas to offer later on. And sometimes even a bad idea can prompt someone else to start thinking in ways that lead them to come up with a good idea. For both of these reasons, it's important to retain widespread interest and morale so that the district can continue to benefit from people's innovative efforts. Active contributors to a district's innovation programs can be recognized through special events, certificates, plaques and the like.

5. Engage the larger community in the innovation journey. Innovation programs represent an opportunity for school districts to involve a wide range of stakeholders, including local companies and nonprofit organizations as well as area colleges and universities. These organizations can serve as a source of "innovation coaches" - i.e., individuals who help to develop and assess particular ideas - and they may also be willing to provide space, materials and other support to the district's innovation efforts. A great way to galvanize community involvement is by including community partners in an annual "innovation event." At such an event, leaders and staff can help cultivate a district's innovation vision and stimulate innovation-related conversations among teachers, parents and other community representatives.

\section{Conclusion}

Observers sometimes assume public schools rely too much on traditional routines, and some assume teachers and administrators are reluctant to embrace the change and innovation needed to help students adjust in a changing world. We know that many public schools are in fact innovative, and we think more schools could be innovative if they were to focus on developing systems that leverage the insight and passion of their own staff. We hope the ideas in this article are useful to people who want to advance innovation within their own schools, and we look forward to learning from others about ways in which district-wide innovation programs can enhance student learning, teacher morale and community engagement.

\section{References}

Brown, T. 2008. Design thinking. Harvard Business Review, June.

Goldstein, D. 2015. The teacher wars: A history of America's most embattled profession. Anchor. 
Kotter, J. \& Rathgeber, H. 2006. Our

iceberg

is

melting:

Changing and succeeding under any conditions. St.

Martin's Press.

Russakoff, D. 2015. The prize: Who's in charge of America's schools. Houghton Mifflin Harcourt. 